\title{
Jalostettavien ominaisuuksien sekä residuaalisen syönnin taloudelliset arvot suomalaisessa maidontuotannossa
}

\author{
P. Hietala ${ }^{1}$, M. Wolfová ${ }^{2}$, J. Wolf $^{2}$, J. Kantanen $^{3}$ ja J. Juga ${ }^{1}$ \\ 1. Maataloustieteiden laitos, Helsingin yliopisto, PL 28, 00014 Helsingin yliopisto, paulii- \\ na.hietala@helsinki.fi \\ 2. Institute of Animal Science, Přátelství 815, CZ-10400 Prague Uhříněves, Tšekki \\ 3. MTT Biotekniikka-ja elintarviketutkimus, 31600 Jokioinen
}

\section{TIIVISTELMÄ}

Tehostamalla lypsykarjan rehun hyväksikäyttökykyä on mahdollista parantaa maidontuotannon taloudellista kannattavuutta. Tämän lisäksi eläinten tehokas rehunkäyttökyky vähentänee maidontuotannon ympäristöön kohdistamaa kuormittavuutta. Rehun hyväksikäytön taloudellista merkitystä lypsylehmien jalostustavoitteessa tutkittiin johtamalla taloudelliset arvot nykyisille jalostettaville ominaisuuksille sekä residuaaliselle kuivaainesyönnille suomalaiselle ayrshirerodulle vuoden 2011 tuotanto-olosuhteissa. Taloudellisten arvojen laskenta perustui bio-ekonomiseen malliin. Tutkimuksessa tarkasteltiin kahta tuotantostrategiaa vasikoille, joita ei tarvittu karjan uudistukseen: A) vasikat myytiin ternivasikoina lypsykarjatilalta ja B) vasikat kasvatettiin lypsykarjatilalla naudanlihantuotantoon. Vuoden 2011 tuotanto- ja markkinaolosuhteissa molemmat tuotantostrategiat tuottivat taloudellista tappiota, kun maataloustukia ei sisällytetty tuottoihin. Strategiassa A tappio oli -616,4 €/lehmä/vuosi ja strategiassa B -962,1 €/lehmä/vuosi. Kun maataloustuet sisällytettiin tuottoihin, molemmat tuotantostrategiat olivat taloudellisesti kannattavia, jolloin tuotto strategiassa A oli 163,4 $€ /$ lehmä/vuosi ja strategiassa B 20,4 €/lehmä/vuosi. Residuaalisen kuiva-ainesyönnin marginaaliseksi taloudelliseksi arvoksi saatiin hiehoilla $-25,5$ ja lehmillä $-55,8 € / \mathrm{kg} \mathrm{ka} / \mathrm{pv}$ lehmää kohti vuodessa. Vastaava marginaalinen taloudellinen arvo lihaksi kasvatettavien eläinten residuaalisessa kuiva-ainesyönnissä oli -29,5 $€ / \mathrm{kg} \mathrm{ka} / \mathrm{pv}$ lehmää kohti vuodessa. Ominaisuuksien taloudelliset arvot skaalattiin keskenään vertailukelpoisiksi kertomalla kunkin ominaisuuden taloudellinen arvo sen geneettisellä hajonnalla. Kun vertailtiin eri ominaisuuksien suhteellista osuutta kaikkien tarkasteltujen ominaisuuksien skaalatuista yhteenlasketuista taloudellisista arvoista, taloudellisesti tärkein ominaisuus oli 305-päivän maitotuotos (34 \% strategiassa A ja $29 \%$ strategissa B) sekä toisiksi tärkein ominaisuus maidon proteiinipitoisuus (13\% strategiassa A ja $11 \%$ strategiassa B). Taloudellisesti kolmanneksi tärkein ominaisuus oli poikimaväli (9\%) tuotantostrategiassa A sekä aikuispaino (11\%) tuotantostrategiassa B. Vuoden 2011 tuotanto-olosuhteissa residuaalisen kuivaainesyönnin taloudellinen merkitys oli suhteellisen alhainen. Sen taloudellinen tärkeys lypsykarjan jalostustavoitteessa kuitenkin tulevaisuudessa todennäköisesti kasvaa johtuen jatkuvasti lisääntyvistä vaatimuksista vähentää maidontuotannon ympäristörasitetta.

\section{Asiasanat}

taloudelliset arvot, rehun hyväksikäyttökyky, residuaalinen syönti, lypsykarja 


\section{Johdanto}

Ruokinta on maidontuotannossa suurin yksittäinen kustannuserä. Tämän vuoksi tehostamalla lypsylehmien rehun hyväksikäyttökykyä olisi mahdollista parantaa maidontuotannon taloudellista kannattavuutta. Tehostamalla nautojen rehun hyväksikäyttöä voidaan myös pienentää maidontuotannon ympäristökuormitusta. Täten lisäämällä parempi rehun hyväksikäyttö osaksi lypsylehmien tämänhetkistä jalostustavoitetta pystyttäisiin samanaikaisesti sekä parantamaan tuotannon kannattavuutta että vähentämään maidontuotannosta aiheutuvaa ympäristörasitetta.

Viime vuosikymmenten aikana saavutettu tuotostason nousu on jo osaltaan epäsuorasti parantanut lehmien rehun hyväksikäyttökykyä, kun ylläpitoon tarvittava rehumäärä on jakautunut useampaa tuotettua maitokiloa kohti. Maitotuotoksen noususta seurannut rehun hyväksikäyttökyvyn paraneminen ei ole kuitenkaan ollut suoraviivaista, sillä lehmien aikauiskoko on kasvanut yhdessä tuotoksen nousun kanssa. Yksi rehun hyväksikäyttökyvyn suora mittari on residuaalinen syönti (RFI) (Koch ym.1963), joka määritetään naudan todellisen rehun syönnin sekä tuotantoon, ylläpitoon ja kasvuun tarvittavan ennustetun rehutarpeen välisenä erotuksena. Määritelmän mukaan ominaisuuden negatiivinen arvo kuvaa tehokkaammin rehua hyväksikäyttävää eläintä verrattuna tarkasteltavan populaation keskiarvoon. Vastaavasti positiivinen arvo kuvaa tehottomammin rehua hyväksikäyttävää eläintä. Residuaalisen syönnin lisäämistä lypsykarjan jalostustavoitteeseen on tähän asti rajoittanut ominaisuuden hankala ja kallis mittaaminen. Tällä hetkellä ominaisuuden mittaamiseen tarvitaan suhteellisen pitkiä ruokintakokeita. Tämän lisäksi lypsykauden aikaiset kuntoluokan ja elopainon muutokset vaikeuttavat ominaisuuden mittaamista lypsylehmillä (Williams ym. 2011). Pryce ym. (2012) määrittämä keskinkertainen arvosteluvarmuus residuaalisen syönnin genomiselle jalostusarvolle holsteinrotuisilla hiehoilla viittaa siihen että tulevaisuudessa genominen valinta voisi mahdollistaa ominaisuuden tehokkaamman jalostusvalinnan lypsykarjalla.

Tämän tutkimuksen tavoitteena oli määrittää taloudelliset arvot residuaaliselle syönnille sekä muille tällä hetkellä jalostettaville ominaisuuksille suomalaiselle ayrshirerodulle vuoden 2011 tuotanto-olosuhteissa. Tämän lisäksi tavoitteena oli selvittää vasikoiden eri markkinointistrategioiden vaikutuksia ominaisuuksien taloudellisiin arvoihin sekä tuotannon kannattavuuteen.

\section{Materiaalit ja menetelmät}

Taloudelliset arvot johdettiin 21:1le eri ominaisuudelle (taulukko 1) bio-ekonomiseen malliin perustuvalla ECOWEIGHT-ohjelmalla (Wolf ym. 2012). Mallissa karjarakenteen simulointi perustui Markovin ketjumenetelmään, jossa karjadynamiikkaa kuvattiin eri eläinluokkina sekä eläinten siirtymisen todennäköisyytenä näiden luokkien välillä. Käytetyt biologiset ja taloudelliset parametrit vastasivat keskimääräisen suomalaisen maidontuotantotilan tuotanto-olosuhteita vuonna 2011. Tutkimuksessa tarkasteltiin kahta tuotantostrategiaa vasikoille, joita ei tarvittu karjan uudistukseen: A) vasikat myytiin ternivasikoina lypsykarjatilalta ja B) vasikat kasvatettiin lypsykarjatilalla naudanlihantuotantoon.

Taulukko 1. Mallissa mukana olleet ominaisuudet ja niiden jaottelu ominaisuusryhmiin.

\begin{tabular}{ll} 
Ominaisuusryhmä & Ominaisuudet \\
$\underline{\text { Tuotanto }}$ & $\begin{array}{l}\text { 305-päivän maitotuotos, valkuaispitoisuus, rasvapitoisuus } \\
\text { poikimaväli, aika hiehon 1. siemennyksestä tiinehtymiseen }\end{array}$ \\
$\underline{\text { Teuras }}$ & $\begin{array}{l}\text { teurasprosentti, lihakkuusluokka, rasvaisuusluokka } \\
\text { poikimavaikeus, vasikkakuolleisuus, vasikkakuolleisuus syntymästä }\end{array}$ \\
$\underline{\text { 6kk:n ikään }}$ & somaattiset solut, utaretulehdusalttius \\
$\underline{\text { Utareterveys }}$ & $\begin{array}{l}\text { syntymäpaino, aikuispaino, teuraaksi kasvatettavien nautojen päiväkasvu, päiväkasvu syn- } \\
\text { tymästä 6kk:n ikään } \\
\text { tuotantoikä }\end{array}$ \\
$\underline{\text { Kestävyys }}$ & residuaalinen kuiva-ainesyönti lehmillä, hiehoilla ja teurasnaudoilla \\
\hline
\end{tabular}

Residuaalinen syönti määritettiin toteutuneen kuiva-ainesyönnin sekä ennustetun kuiva-ainesyönnin välisenä erotuksena erikseen lehmille, kasvaville hiehoille (180 päivän iästä poikimiseen) sekä teurasnaudoille (180 päivän iästä teurastukseen). Ennustetun kuiva-ainesyönnin määritys perustui kasvuun, tiineyteen, ylläpitoon sekä tuotantoon tarvittavaan nettoenergian sekä valkuaisentarpeen (ohutsuolessa imeytyvä 
valkuinen, PDI) täyttymiseen. Kunkin eläinryhmän energia- ja valkuaistarpeen määrittäminen perustui tarvenormeihin, joista Wolf ym. (2012) on antanut yhteenvedon. Todellinen kuiva-ainesyönti määritettiin ennustetun kuiva-ainesyönnin sekä eläinryhmän keskimääräisen residuaalisen kuiva-ainesyönnin summana. Perustuen residuaalisen syönnin määritelmään (Williams ym. 2011), jokaisen eläinryhmän residuaalisen kuiva-ainesyönnin keskiarvo oletettiin nollaksi. Toisin sanoen todellisen kuiva-ainesyönnin keskiarvo oletettiin yhtä suureksi ennustetun kuiva-ainesyönnin keskiarvon kanssa.

Tuotannon nettovoitto/tappio määritettiin diskontattujen tuottojen ja kustannusten välisenä erotuksena lehmää kohti vuodessa. Tuottojen ja kustannusten ilmentymisajankohta huomioitiin mallissa diskonttaamalla kaikki tuotot ja kustannukset jälkeläisen syntymäajankohtaan. Tuotannon nettovoitto/tappio laskettiin seuraavasti: Voitto $=\boldsymbol{t u o t t o}^{\prime} \times \boldsymbol{N} \boldsymbol{D} \boldsymbol{E}^{(\text {tuotto })}-\boldsymbol{k} \boldsymbol{u} \boldsymbol{s t}^{\prime} \times \boldsymbol{N} \boldsymbol{D} \boldsymbol{E}^{(\boldsymbol{k} u s t)}$ missä Voitto on tuotannon nettovoitto/tappio, tuotto' ja kust' ovat tuottojen ja kustannusten vektorit ja $\mathbf{N D E}^{\text {(tuotto) }}$ sekä $\mathbf{N D E}{ }^{\text {(kust) }}$ ovat tuottojen ja kustannusten diskontattujen kertymien vektorit. Diskonttokorkona oli $5 \%$.

Taulukko 2. Keskeisimmät tuottojen ja kustannusten määrittämiseen käytetyt parametrit.

\begin{tabular}{|c|c|c|c|}
\hline Tuotot & & Kustannukset & \\
\hline Maidon perushinta (sisältää jälkitilin) (snt/kg) ${ }^{1}$ & 41,7 & Rehuannos $(€ / \mathrm{kg})$ & \\
\hline Rasva-\% (snt/\%) & 2,3 & Lehmät & 0,06 \\
\hline Valkuais-\% (snt/\%) & 6,3 & Hiehot & 0,04 \\
\hline I-luokan hinta-alennus (snt/kg) ${ }^{2}$ & 2,5 & Teurasnaudat & 0,05 \\
\hline II-luokan hinta-alennus (snt/kg) ${ }^{3}$ & 31 & Kiinteät kustannukset (€/eläin/pv) & \\
\hline ks-jalostusohjelmaan myyty sonnivasikka (€/vasikka) & 3700 & Lehmät & 6,7 \\
\hline Sonnivasikka (€/vasikka) & 154 & Hiehot & 1,1 \\
\hline Lehmävasikka (€/vasikka) & 82 & Vasikat & 1,1 \\
\hline Lietelanta $(€ / 100 \mathrm{~kg})$ & 0,52 & Teurassonnit & 0,9 \\
\hline & & Teurashiehot & 1,2 \\
\hline & & 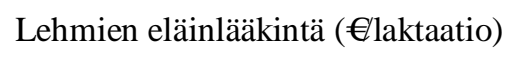 & 110 \\
\hline & & Utaretulehdushoidot (€/hoito) & 160 \\
\hline & & Poikimavaikeushoidot ( $€$ /hoito) & 268 \\
\hline & & Siemennysmaksu (€/annos) & 33 \\
\hline & & Kuivitus (€/kg) & 0,16 \\
\hline
\end{tabular}

${ }^{\mathrm{T}}$ Perushinta maidolle, joka sisältää 4,3 \% rasvaa, 3,3 \% valkuaista ja somaattinen soluluku on alle 250000 solua/ml

${ }^{2}$ Maidon somaattinen soluluku välillä 250000- 400000 solua/ml

${ }^{3}$ Maidon somaattinen soluluku yli 400000 solua/ml

Mallissa tuotot muodostuivat maidon, lihan ja välitysvasikoiden myyntituloista sekä lannan rahallisesta arvosta (taulukko 2). Maidosta saadut myyntitulot määräytyivät keksimääräisen lehmäkohtaisen vuosituotoksen sekä keskimääräisen maidon hinnan perusteella. Maidon hinnoittelussa huomioitiin rasva- ja valkuaispitoisuus sekä maidon laatu. Teurastetuista eläimistä saatuihin tuottoihin vaikuttivat eläimen elopaino teurastushetkellä, teurasprosentti sekä ruhon rasva- ja lihakkuusluokka. Maataloustukien osalta tarkasteltiin kahta eri skenaariota, joissa tuet joko sisällytettiin tuottoihin tai jätettiin mallissa huomioimatta.

Kustannukset koostuivat kiinteistä kustannuksista sekä ruokinta-, kuivitus-, siemennys- ja eläinlääkintäkustannuksista, jotka määritettiin erikseen kullekin eläinryhmälle. Kiinteät kustannukset sisälsivät työ-, kone-, rakennus-, sekä yleiskustannukset. Eläinryhmäkohtaisten ruokintakustannusten laskenta perustui rehumäärään joka tarvittiin täyttämään laskennallinen päivittäinen energian ja valkuaisen tarve. Käytetyt rehujen hinnat perustuivat ProAgrian tuottopehtorissa (ProAgria,2013) käytettyihin rehuhintoihin vuodelle 2011.

Ominaisuuksien marginaaliset taloudellisten arvot määritettiin voittofunkiton osittaisderivaattana kunkin ominaisuuden suhteen seuraavasti: $e v_{t}=\left(\right.$ Voitto $_{n}-$ Voitto $\left._{l}\right) /\left(O A_{n}-O A_{l}\right)$ missä $e v_{t}$ on ominaisuuden $t$ taloudellinen arvo ilmaistuna lehmää kohti vuodessa, Voitton ja Voitto $o_{l}$ ovat tuotannosta saatavat nettovoitot/tappiot ominaisuuden $t$ keskiarvon nousun ja laskun jälkeen sekä $O A_{n}$ ja $O A_{l}$ ovat ominaisuuden $t$ arvot ominaisuuden keskiarvon nousun ja laskun jälkeen. Kun ominaisuutta vastaava muuttuja oli jatkuva, ominaisuuden keskiarvoa nostettiin ja laskettiin $0,5 \%$. Koska residuaalisen syönnin keskiarvo oletettiin nollaksi kaikille eläinryhmille, sen taloudellista arvoa laskettaessa ominaisuuden keskiarvoon lisättiin ja siitä vähen- 
nettiin $0,05 \mathrm{~kg} \mathrm{ka} / \mathrm{pv}$. Kun johdettiin taloudellisia arvoja ominaisuuksille, jotka olivat luonteeltaan diskreettejä, siirrettiin taustalla olevaa normaalijakaumaa vasemmalle sekä oikealle 0,5 hajonnan yksikköä. Eri ominaisuuksien erilainen ilmentymisajankohta huomioitiin mallissa kertomalla ominaisuuden taloudellinen arvo ominaisuuden diskontatulla kertymällä. Tämän lisäksi ominaisuuksien taloudelliset arvot skaalattiin keskenään vertailukelpoisiksi kertomalla kunkin ominaisuuden taloudellinen arvo sen geneettisellä hajonnalla.

\section{Tulokset ja tulosten tarkastelu}

Vuoden 2011 tuotanto- ja markkinaolosuhteissa molemmat markkinointistrategiat tuottivat taloudellista tappiota, kun maataloustukia ei sisällytetty tuottoihin. Strategiassa A tappio oli - $616,4 € /$ lehmä/vuosi ja strategiassa B -962,1 €/lehmä/vuosi. Kun maataloustuet sisällytettiin tuottoihin, molemmat strategiat olivat taloudellisesti kannattavia, jolloin tuotto strategiassa A oli 163,4 €/lehmä/vuosi ja strategiassa B 20,4 €/lehmä/vuosi. Maataloustuilla oli merkittävä vaikutus tuotannon kannattavuuteen sillä ne kattoivat molemmissa vasikoiden markkinointistrategioissa noin $20 \%$ kokonaistuotoista (C1 tukialue). Ominaisuuksien taloudellisia arvoja johdettaessa maataloustukien sisällyttäminen tuottoihin on kuitenkin ollut kiistanalaista johtuen nykyisen tukisysteemin jatkuvuuden epävarmuudesta. Tämän lisäksi maataloustukein määrät vaihtelevat merkittävästi eri tukialueiden kesken, mikä johtaa ominaisuuksien taloudellisten arvojen suuriin eroihin eri tukialueilla.

Ominaisuuksien marginaaliset taloudelliset arvot (taulukko 3) kuvaavat tuotannon kokonaisvoiton muutosta ilmaistuna lehmää kohti vuodessa, kun ominaisuuden keskiarvoa nostettaan yhdellä yksiköllä. Kun maataloustukia ei sisällytetty tuottoihin strategiassa B, poikimavaikeuden, vasikkakuolleisuuden sekä vasikkakuolleisuuden 6kk:n ikään marginaaliset taloudelliset arvot olivat positiivisia. Kyseisten ominaisuuksien keskiarvon nousun seurauksena teuraaksi kasvatettavien nautojen määrä vähenee. Näiden ominaisuuksien positiiviset taloudelliset arvot ovat pääosin seurausta heikosta kannattavuudesta kasvattaa vasikoita naudanlihantuotantoon. Sitä vastoin kun maataloustuet lisättiin tuottoihin strategiassa B, poikimavaikeuden sekä vasikkakuolleiden 6kk:n ikään marginaaliset taloudelliset arvot olivat negatiivisia johtuen lihanautojen kasvatuksen paremmasta kannattavuudesta maataloustukien ansiosta.

Kun vertailtiin eri ominaisuuksien suhteellista osuutta kaikkien tarkasteltujen ominaisuuksien skaalatuista yhteenlasketuista taloudellisista arvoista, taloudellisesti tärkein ominaisuus oli 305-päivän maitotuotos (34 \% strategiassa A ja $29 \%$ strategissa B) sekä toisiksi tärkein ominaisuus maidon proteiinipitoisuus (13\% strategiassa A ja $11 \%$ strategiassa B). Taloudellisesti kolmanneksi tärkein ominaisuus oli poikimaväli (9\%) tuotantostrategiassa A sekä aikuispaino (11\%) tuotantostrategiassa B.

Ominaisuuksien taloudellisissa painoissa löytyi huomattavia eroja vasikoiden markkinointistrategioiden välillä (kuva 1). Kun tarkastellaan yksittäisen maitotilan tuotannon kannattavuutta, voisi olla hyödyllistä rakentaa kaksi valintaindeksiä tilatasolla tapahtuvaa sonnien valintaa varten. Näin tilat pystyisivät valitsemaan taloudellisesti sopivimmat sonnit omalle tuotantostrategialleen. Koska Suomessa maidon- ja naudanlihantuotanto ovat voimakkaasti toisiinsa kytkeytyneitä, tulisi keinosiemennyssonnien valinnassa huomioida samanaikaisesti taloudellisesti kannattavamman maidon- ja naudanlihantuotannon tavoite.

Kun tarkasteltiin eri ominaisuusryhmien taloudellista merkitystä, tuotosominaisuudet olivat selvästi tärkein ominaisuusryhmä molemmissa vasikoiden markkinointistrategioissa. Kun verrataan tämän tutkimuksen tuloksia ominaisuuksien taloudelliseen merkitykseen pohjoismaisessa jalostustavoitteessa, tuotantoominaisuudet saavuttivat huomattavasti korkeamman taloudellisen painoarvon tässä tutkimuksessa kuin mikä niillä oli määritettäessä Nordic Total Merit (NTM) indeksin taloudellisia lähtökohtia (Pedersen ym. 2008).

Residuaalisen kuiva-ainesyönnin yhteenlaskettu suhteellisten taloudellisten painojen osuus oli noin 6$7 \%$ vasikoiden markkinointistrategiasta riippuen. Vaikka reisiduaalisen kuiva-ainesyönnin taloudellinen merkitys tässä tutkimuksessa oli suhteellisen alhainen, saattaa sen painoarvo tulevaisuudessa lisääntyä johtuen kasvavista vaatimuksista pienentää kotieläintuotannon ympäristörasitetta. Kun tarkastellaan tässä tutkimuksessa mukana olleita ominaisuuksia, mahdollisen ympäristöverotuksen aiheuttama rehun hinnan nousu tulisi siirtämään taloudellista painoa tuotanto-ominaisuuksilta etenkin residuaaliselle kuiva-ainesyönnille sekä lehmien aikuispainolle suosien kevyempiä eläimiä. 
Taulukko 3. Ominaisuuksien keskiarvot $(\mathrm{ka})$, geneettiset hajonnat $\left(\mathrm{sd}_{\mathrm{a}}\right)$ ja marginaaliset taloudelliset arvot (€/yks./lehmä/vuosi)

\begin{tabular}{|c|c|c|c|c|c|c|}
\hline \multirow[b]{3}{*}{ Ominaisuus (yks.) } & \multirow[b]{3}{*}{$\mathrm{ka}$} & \multirow[b]{3}{*}{$\mathrm{sd}_{\mathrm{a}}$} & \multicolumn{2}{|c|}{ Tuotantotuet } & \multicolumn{2}{|c|}{ Ei tuotantotukia } \\
\hline & & & \multicolumn{3}{|c|}{ Strategia $^{1}$} & \multirow[b]{2}{*}{ B } \\
\hline & & & A & $\mathrm{B}$ & $\mathrm{A}$ & \\
\hline 305-päivän maitotuotos $(\mathrm{kg})^{2}$ & 8862 & 562,4 & 0,3 & 0,3 & 0,4 & 0,4 \\
\hline Valkuaispitoisuus (\%) & 3,44 & 0,15 & 404,5 & 404,5 & 404,5 & 404,5 \\
\hline Rasvapitoisuus (\%) & 4,27 & 0,34 & 109,0 & 109,0 & 109,0 & 109,0 \\
\hline $\mathrm{SCS}^{3}$ & 2,6 & 0,085 & $-84,3$ & $-84,3$ & $-84,3$ & $-84,3$ \\
\hline Utaretulehdusalttius (tapaus/lehmä/vuosi) & 0,11 & 0,04 & $-389,4$ & $-389,4$ & $-389,4$ & $-389,4$ \\
\hline Poikimavaikeus (luokka) & 1,35 & 0,16 & $-22,1$ & 4,6 & $-25,8$ & $-14,6$ \\
\hline Vasikkakuolleisuus $(\%)^{4}$ & 4,2 & 2,5 & $-0,3$ & 5,6 & $-0,3$ & 2,1 \\
\hline Vasikkakuolleisuus 6kk:n ikään (\%) & 3,0 & 2,0 & $-1,3$ & 3,1 & $-1,3$ & $-0,4$ \\
\hline Tuotantoikä (vuosi) & 2,8 & 0,24 & 88,2 & 17,2 & 121,9 & 91,9 \\
\hline Syntymäpaino (kg) & 39 & 4,2 & $-0,2$ & 0,5 & $-0,2$ & 0,5 \\
\hline Aikuispaino (kg) & 624 & 33,9 & $-1,0$ & $-1,7$ & $-1,0$ & $-1,7$ \\
\hline Teurasprosentti $(\%)^{5}$ & 50 & 1,14 & 2,8 & 10 & 2,8 & 10 \\
\hline Päiväkasvu syntymästä 6kk:n ikään (g/pv) ${ }^{4}$ & 800 & 60 & 0,3 & 0,3 & 0,3 & 0,3 \\
\hline Teurasnautojen päiväkasvu $(\mathrm{g} / \mathrm{pv})^{4}$ & 800 & 47 & - & 0,4 & - & 0,4 \\
\hline Rasvaisuusluokka $^{5}$ & 2,86 & 0,21 & $-7,6$ & $-13,1$ & $-7,6$ & $-13,1$ \\
\hline Lihakkuusluokka ${ }^{5}$ & 8,52 & 0,38 & $-0,2$ & $-8,2$ & $-0,2$ & $-8,2$ \\
\hline Poikimaväli (pv) & 413 & 8,98 & $-4,8$ & $-1,6$ & $-4,8$ & $-1,6$ \\
\hline Aika hiehon 1. siemennyksestä tiinehtymiseen (pv) & 20 & 6,6 & $-1,6$ & $-1,4$ & $-1,6$ & $-1,4$ \\
\hline Residuaalinen ka-syönti teurasnaudoilla (kg ka/pv) & 0 & 0,27 & - & $-29,5$ & - & $-29,5$ \\
\hline Residuaalinen ka-syönti hiehoilla (kg ka/pv) & 0 & 0,27 & $-25,5$ & $-25,5$ & $-25,5$ & $-25,5$ \\
\hline Residuaalinen ka-syönti lehmillä (kg ka/pv) & 0 & 0,38 & $-55,8$ & $-55,8$ & $-55,8$ & $-55,8$ \\
\hline
\end{tabular}

${ }^{\mathrm{T}}$ Strategia A: vasikat myydään ternivasikoina, Strategia B: vasikat kasvatetaan tilalla naudanlihantuotantoon

${ }^{2}$ Maito keskimääräisellä 4,3\%:n valkuaispitoisuudella ja 3,4\%:n rasvapitoisuudella

${ }^{3} \mathrm{SCS}=\log _{2}$ ( somaattinen soluluku/100000)+3

${ }^{4}$ Keskiarvo on annettu lehmävasikalle mutta ominaisuuden taloudellisessa arvossa on huomioitu molemmat sukupuolet ${ }^{5}$ Keskiarvo on annettu hiehoille mutta ominaisuuden taloudellisessa arvossa on huomioitu kaikki eläinryhmät (sonnit, hiehot ja lehmät)

Kuva 1. Ominaisuuksien suhteelliset taloudelliset painot ominaisuusryhmittäin, kun maataloustukia ei huomioitu mallissa.

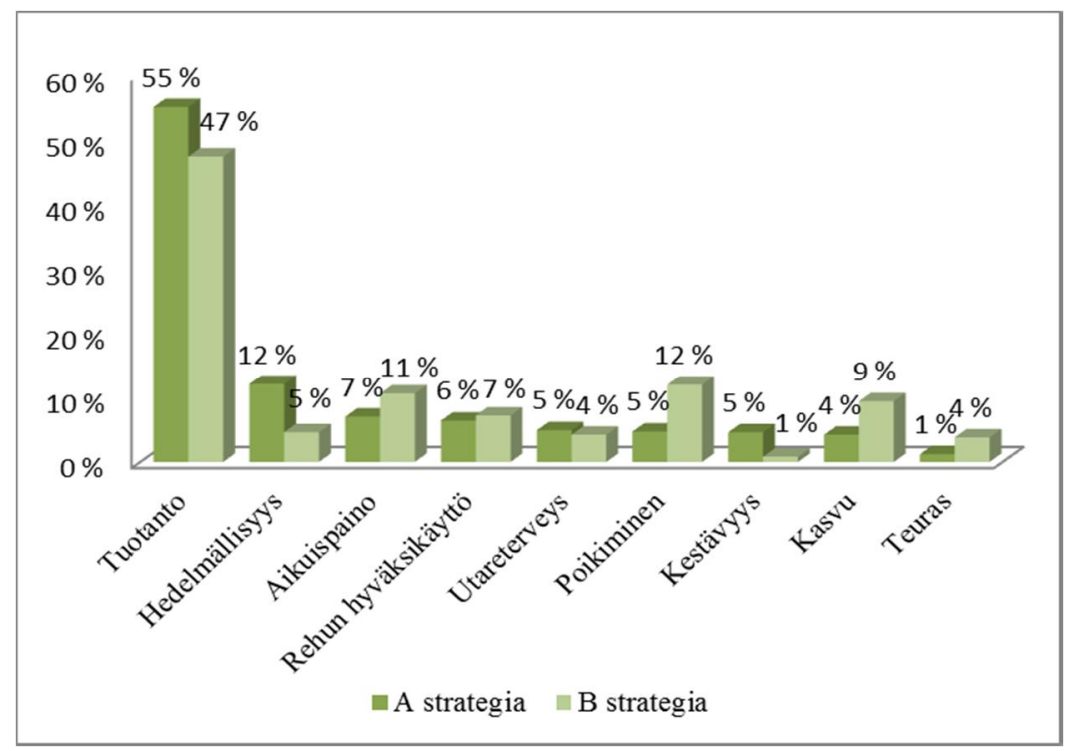




\section{Johtopäätökset}

Tämän tutkimuksen tulokset osoittavat että suomalaisen maidontuotannon kannattavuus on pitkälti maataloustukien varassa. Kun ajatellaan ominaisuuksien taloudellisten arvojen määrittämistä, on kuitenkin kiistanalaista tulisiko maataloustuet ottaa laskennassa huomioon johtuen nykyisen tukisysteemin jatkuvuuden epävarmuudesta tulevaisuudessa. Ominaisuuksien taloudellisissa painoissa löytyi merkittäviä eroja vasikoiden markkinointistrategioiden välillä. Tulosten perusteella voisi olla kannattavaa rakentaa kaksi eri valintaindeksiä käytettäväksi sonnien valinnassa tilatasolla riippuen tuotantosysteemistä. Vuoden 2011 tuotantoolosuhteissa residuaalisen kuiva-ainesyönnin taloudellinen merkitys oli suhteellisen alhainen. Sen taloudellinen tärkeys lypsykarjan jalostustavoitteessa kuitenkin tulevaisuudessa todennäköisesti kasvaa johtuen jatkuvasti lisääntyvistä vaatimuksista vähentää maidontuotannon ympäristörasitetta.

\section{Kirjallisuus}

Koch, R. M., Swiger, L. A., Chambers, D. \& Gregory, K. E. 1963. Efficiency of feed use in beef cattle. J. Anim. Sci. 22:486-494.

Pedersen, J., Sørensen, M. K., Toivonen, M., Eriksson, J-Å. \& Aamand, G. P. 2008. Report on Economic basis for a Nordic Total Merit Index evaluation. http://www.nordicebv.info/NR/rdonlyres/B618C0E5-FF6F-4D31-8F86 B3CE4A140043/0/NAV_TMI_report_lastversion_131108.pdf

ProAgria. 2013. Tuottopehtorin mallilaskelmat. ProAgria Keskusten Liitto. http://www.proagria.fi/tuottopehtori/

Pryce, J. E., Arias, J., Bowman, P. J., Davis, S. R., Macdonald, K. A., Waghorn, G. C., Wales, W. J., Williams, Y. J., Spelman, R. J. \& Hayes B. J. 2012. Accuracy of genomic predictions of residual feed intake and 250-day body weight in growing heifers using 625,000 single nucleotide polymorphism markers. J. Dairy Sci. 95:2108-2119.

Williams, Y. J., Pryce, J. E., Grainger, C., Wales, W. J., Linden, N., Porker, M. \& Hayes, B. J. 2011. Variation in residual feed intake in Holstein-Friesian dairy heifers in southern Australia. J. Dairy Sci. 94:4715-4725.

Wolf, J., Wolfová, M. \& Krupa, E. 2012. User's Manual for the Program Package ECOWEIGHT (C Programs for Calculating Economic Weights in Livestock), Version 5.3.2. Part 1: Programs EWBC (Version 2.3.1) and EWDC (Version 2.2.3) for Cattle. Praha-Uhříněves, Institute of Animal Science, Czech Republic. 